The Harvard Kennedy School Misinformation Review ${ }^{1}$

April 2020, Volume 1, Special Issue on COVID-19 and Misinformation

Attribution 4.0 International (CC BY 4.0)

Reprints and permissions: misinforeview@hks.harvard.edu

DOI: https://doi.org/10.37016/mr-2020-015

Website: misinforeview.hks.harvard.edu

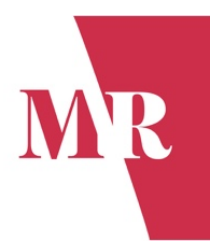

\title{
Why do people believe COVID-19 conspiracy theories?
}

As conspiracy theories about COVID-19 take root in the United States, understanding the psychological foundations of conspiracy beliefs is increasingly critical. Our research shows that beliefs in two popular variants of COVID-19 conspiracy theory are the joint product of the psychological predispositions 1) to reject information coming from experts and other authority figures and 2) to view major events as the product of conspiracies, as well as partisan and ideological motivations. The psychological foundations of conspiracy beliefs have implications for the development of strategies designed to curtail their negative consequences.

Authors: Joseph E. Uscinski (1), Adam M. Enders (2), Casey Klofstad (3), Michelle Seelig (4), John Funchion (5), Caleb Everett (6), Stephan Wuchty (7), Kamal Premaratne (8), Manohar Murthi (9)

Affiliations: (1,3) Political Science, University of Miami; (2) Political Science, University of Louisville, (4) Cinema and Interactive Media, University of Miami; (5) English, University of Miami; (6) Anthropology, University of Miami; (7) Computer Science and Institute of Data Science and Computing, University of Miami; $(8,9)$ Electrical and Computer Engineering, University of Miami

How to cite: Uscinski, Joseph E.; Enders, Adam M.; Klofstad, Casey A.; Seelig, Michelle I.; Funchion, John, R.; Everett, Caleb; Wuchty, Stephan; Premaratne, Kamal; Murthi, Manohar, N. (2020). Why do people believe COVID-19 conspiracy theories?, The Harvard Kennedy School (HKS) Misinformation Review, Volume 1, Special Issue on COVID-19 and Misinformation Received: March 23, 2020 Accepted: April 24, 2020 Published: April 28, 2020

\section{Research questions}

- How widespread are beliefs about COVID-19 conspiracy theories?

- What psychological, social, and political factors explain COVID-19 conspiracy beliefs?

- Can partisanship and cues from partisan leaders, such as the president, increase misinformation about COVID-19?

\section{Essay summary}

- Using a representative survey of U.S. adults fielded March 17-19, 2020 ( $n=2,023)$, we examine the prevalence and correlates of beliefs in two conspiracy theories about COVID-19.

- $29 \%$ of respondents agree that the threat of COVID-19 has been exaggerated to damage President Trump; $31 \%$ agree that the virus was purposefully created and spread.

- The strongest predictors of beliefs in these ideas are a psychological predisposition to reject expert information and accounts of major events (denialism), a psychological predisposition to view major events as the product of conspiracy theories (conspiracy thinking), and partisan and ideological motivations.

\footnotetext{
${ }^{1}$ A publication of the Shorenstein Center on Media, Politics and Public Policy at Harvard University's John F. Kennedy School of Government.
} 
- Support for Donald Trump is strongly related to the belief that the COVID-19 threat has been exaggerated, even when accounting for partisanship and ideology. This relationship is strongest among people who regularly pay attention to politics. We surmise that Trump supporters adopted this belief in response to the President's early messaging about the virus.

- Belief that the virus was spread on purpose is most related to conspiracy thinking and is only slightly more concentrated among self-identified Republicans and conservatives than Democrats and liberals. This is likely a consequence of the fact that only a few, less salient partisan elites have endorsed this theory.

\section{Implications}

Conspiracy beliefs - especially those regarding science, medicine, and health-related topics - are widespread (Oliver and Wood 2014) and capable of prompting people to eschew appropriate healthrelated behaviors (Jolley and Douglas 2014). These (in)actions can result in negative societal consequences that reach beyond the individual conspiracy believer (e.g., failing to vaccinate one's children can contribute to a resurgence in once eradicated diseases). A primary step in any initiative to correct harmful beliefs is to understand their characteristics and sources. If we understand who believes in conspiracy theories and misinformation about COVID-19 and why they hold such beliefs, we can better inform strategies to mitigate the harmful effects of the beliefs.

We find that the psychological predisposition to reject expert, authoritative information (denialism), the tendency to view major social and political events as the product of conspiracies (conspiracy thinking), and partisan motivations are the strongest explanatory factors behind COVID-19 conspiracy beliefs. Because two of these factors - conspiracy thinking and denialism - are founded in a deep distrust of experts and authority figures (e.g., scientists, political leaders), correction of misinformed and conspiratorial beliefs among individuals who exhibit high levels of conspiracy thinking and denialism is likely to be difficult. Conspiracy theorists and denialists are simply unlikely to accept corrective information coming from experts. This link between conspiracy thinking and misinformation has been highlighted as a potential reason for the observed failure of corrective strategies in several health-related cases (Carey, et al. 2020).

Despite this difficulty, it is not altogether impossible to limit the negative effects of misinformation and conspiracy theories, especially when the third factor - partisanship - can be mobilized in this effort. We identify three strategies for overcoming these negative effects. First, we might aim to limit the spread of, or exposure to, misinformation and conspiracy theories in the first place, or attempt to "pre-bunk" the dubious claims at the center of such ideas. These strategies take the perspective that our efforts should be as focused on prevention as they are on treatment, and recent efforts in this vein have proven successful despite legal and practical complications with impeding the communication of certain types of ideas (Roozenbeek, van der Linden and Nygren 2020).

Second, future work might employ existing knowledge about the correlates of conspiracy thinking and denialism to construct new strategies for limiting the effects of these predispositions on subsequent beliefs. For example, Douglas and colleagues $(2017,538)$ find that both conspiracy thinking and specific conspiracy beliefs are oftentimes the product of "epistemic (e.g., the desire for understanding, accuracy, and subjective certainty), existential (e.g., the desire for control and security), and social (e.g., the desire to maintain a positive image of the self or group)" motivations. If, then, we can generate preventive and corrective strategies that reduce uncertainty, increase perceived control, or promote a positive selfimage, for example, we may be able to limit the power of people's predispositions to construct conspiratorial accounts of major events or deny expert information (Nyhan and Reifler 2019).

Third, evidence suggests that corrective strategies can be efficacious if other political and social ingredients of conspiracy beliefs can be mobilized to correct beliefs (e.g., Berinsky 2015). Partisan and 
ideological motivations - both of which underlie the COVID-19 conspiracy beliefs we examine here - are prime examples of such ingredients. Even though conspiracy thinking and denialism may lead one to reject the information and accounts of many experts and authority figures, partisanship supplies trusted authority figures in the form of co-partisan leaders. If, then, partisan identity can be activated and mobilized, it may prove capable of overriding the distrust at the center of conspiratorial and denialist tendencies. A central mechanism by which this mobilization can occur is elite cueing (Zaller 1992), and the motivated reasoning it engages (Miller, Saunders and Farhart 2016). When party leaders and media personalities promote conspiracy theories and misinformation, likeminded individuals exposed to this rhetoric are more likely to adopt those ideas (Swire, et al. 2017).

We present evidence below that cues from partisan elites are capable of fostering, rather than correcting, conspiracy beliefs. To see how, consider the political information environment in the U.S. in the early months of 2020. At the outset of the COVID-19 threat, President Trump referred to COVID-19 as "their [Democrats'] new hoax" (Rieder 2020), and repeatedly likened the threat to the common flu (Brooks 2020). This likely led his supporters to take COVID-19 less seriously - a proposition we find support for. Less visible Republican leaders, such as Senator Tom Cotton, hinted that the virus was a bioweapon (Stevenson 2020); this rhetoric, albeit to a lesser extent, also likely encouraged some Republicans to adopt related beliefs. Moreover, Fox News personalities and other right-wing media figures continue to cast aspersions on the threat of COVID-19, even going so far as to question whether hospitals are truly filled with infected patients (Peters 2020).

If cues from partisan elites are capable of inflaming conspiracy beliefs among likeminded supporters, they may also capable of reducing conspiracy beliefs and limiting their pernicious effects. In these instances, the distrust at the center of conspiracy thinking and denialism may be overridden by embracing the power of partisanship and conveying corrective information using likeminded political elites (Berinsky 2015, Benegal and Scruggs 2018). This strategy seems particularly promising in the case of COVID-19. Since our survey was fielded, Donald Trump has publicly acknowledged the threat in daily White House briefings - an action that seems to have made Republicans more concerned about the virus (Badger and Quealy 2020).

On the one hand, this provides suggestive evidence for the efficacy of corrective partisan cues; on the other, it suggests a potential limitation of our study. Our results - from a survey fielded in mid-March provide but a snapshot of COVID-19 conspiracy beliefs in a continually developing sociopolitical context. Changes in the behavior of Donald Trump and other political leaders who previously hinted at the possibility of a conspiracy or who trafficked in misinformation may operate as a corrective cue of sorts, encouraging supporters to take the threat seriously and engage in preventive measures. This is especially the case as other facts - e.g., the toll on human life - become increasingly apparent and unassailable.

That said, we possess ample evidence that these and similar COVID-19 conspiracy theories continue to spread and generate negative societal consequences. For example, three weeks after our data was collected a train operator working at the Port of Los Angeles attempted to crash a train into a Navy hospital ship because he "wanted to bring attention to the government's activities" regarding the COVID19 response (Zaveri 2020). In the UK, people who allegedly believe that $5 \mathrm{G}$ cellular networks are the cause of COVID-19 set fire to multiple cell towers (Slotkin 2020). These events suggest that our findings and their implications may traverse the trappings of the particular conspiracy theories we queried and the timeline of data collection.

They also suggest some nuance to the strategy of correction via co-partisan sources. Even though many political leaders who once trafficked in misinformation about the virus have begun to take it seriously, few have explicitly and unequivocally disavowed the misinformation and conspiracy theories. Even copartisan corrections to misinformation require more than simply changing the conversation or quietly changing course; rather, dubious information needs to be actively discredited for a "correction" to be effective. Moreover, some negative consequences of misinformation and conspiratorial rhetoric cannot 
fully be reversed (Thorson 2015). During health crises like the COVID-19 pandemic or measles outbreaks, post-hoc changes in beliefs are simply not as valuable as the preventive actions - social distancing, handwashing, vaccinations - that are consequentially stymied by such misinformed beliefs in the early stages of a crisis.

\section{Findings}

Finding 1: COVID-19 conspiracy beliefs are widespread.

We asked respondents to what extent they agreed with the ideas that the COVID-19 threat "has been exaggerated" or "purposely created and released." While the distributions of responses in Figure 1 reveal that there are more individuals who generally disagree with the propositions than agree, levels of agreement are far from trivial. Indeed, over $29 \%$ of respondents agree that the threat posed by COVID-19 is being exaggerated, while more than $31 \%$ agree that virus was intentionally created and spread. Given the transmissibility of COVID-19, these beliefs are dangerous even if only a fraction of Americans succumbing to them ignore best practices, such as social distancing.

COVID-19 Threat Exaggerated

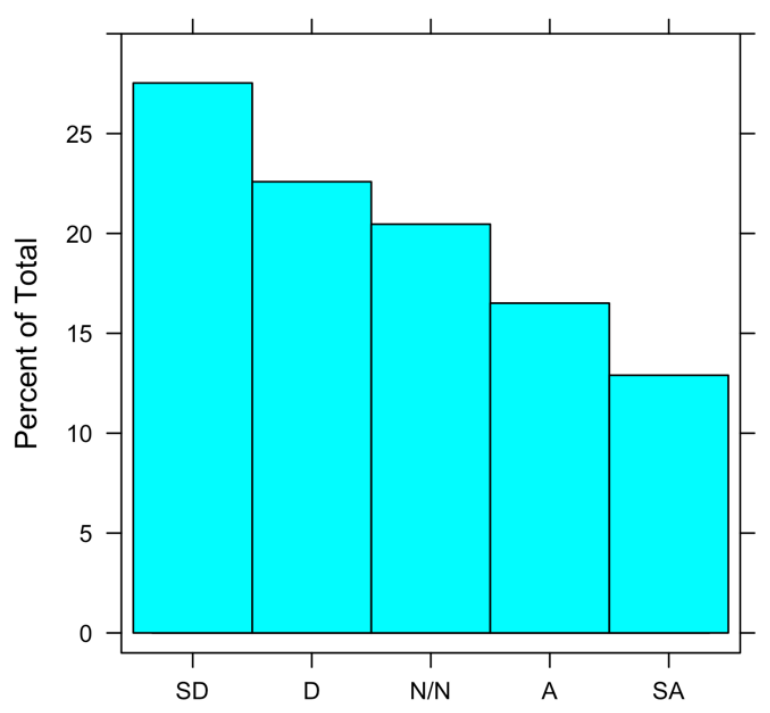

COVID-19 Spread on Purpose

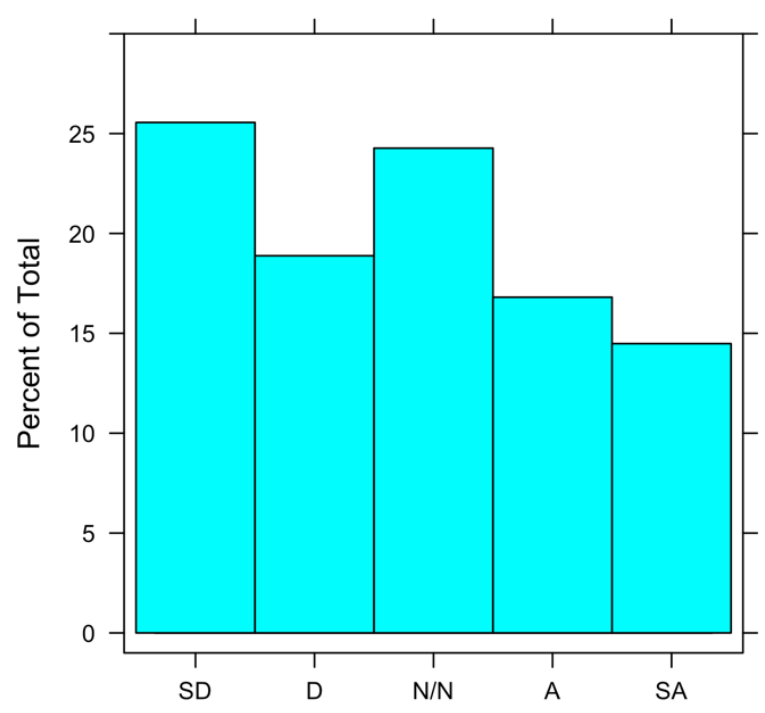

Figure 1. Distribution of beliefs that COVID-19 "threat is exaggerated" and was "spread on purpose". "SA"=strongly agree, "N/N"=neither agree/nor disagree, "SD"=strongly disagree. The mean on the left panel is 1.65 on a $0-4$ scale; mean on the right is 1.76 .

Even though they are related to a number of individual traits - see Finding 2 - these beliefs persist across a number of political and sociodemographic factors. Perhaps most strikingly, there is no correlation between educational attainment and either conspiracy belief, suggesting that these beliefs are not merely the product of deficient health education, but one of psychological and political motivations.

Finding 2: A mixture of psychological and political motivations explain COVID-19 conspiracy beliefs. 
In Figure 2 we show that COVID-19 conspiracy beliefs are strongly related to several psychological and political factors. The farther each plotting symbol (red circles for the "threat exaggerated" belief, blue triangles for "spread on purpose") is to the left or right of the vertical dashed line, 0 , the stronger the relationship between the conspiracy belief and the variable listed along the left-hand side of the figure. Because, for example, the blue triangular symbol associated with conspiracy thinking is farther from the vertical dashed line than any other symbol, we know it is more strongly associated with "spread on purpose" conspiracy beliefs than any other factor. Altogether, Figure 2 reveals that conspiracy thinking, denialism, partisanship, ideology, religiosity, and youth are all consistently related to COVID-19 conspiracy beliefs, albeit to vary degrees.

We also showcase the relationships between key explanatory factors and conspiracy beliefs in Figure 3. When it comes to the "spread on purpose" belief, individuals exhibiting the lowest degrees of conspiracy thinking register beliefs somewhere between "strongly disagree" and "disagree," while respondents on the high end "agree," on average (top left panel). Such an effect - the strongest one we observe - is remarkable, especially considering that other factors are taken into account. We also find that individuals that are least likely to reject authoritative information "disagree" with the "spread on purpose" theory, while those most likely to reject experts and authorities fall somewhere between neutrality and agreement. Given the relatively flat blue lines in the bottom panels of Figure 3, "spread on purpose" beliefs are only very weakly related to partisanship and ideology, as we would expect given the relative lack of attention to this conspiracy theory by political elites and mainstream news outlets.

Patterns differ in key ways when it comes to the "threat exaggerated" belief, with partisanship and denialism exhibiting stronger associations than conspiracy thinking, and ideology also proving to be more strongly related. The partisan and ideological connections, as we demonstrate below, are likely a consequence of President Trump and other Republican/conservative elites publicly lending credence to this idea. Given the potential for elites to influence mass opinion, it makes theoretical sense that Republicans and conservatives in the mass public are more likely to believe the threat has been exaggerated.

Differences in the correlates of the "threat exaggerated" and "spread on purpose" conspiracy beliefs comport nicely with the patterns associated with other conspiracy beliefs that have similar properties (Smallpage, Enders and Uscinski 2017). For example, "threat exaggerated" beliefs are more highly correlated $(r=0.56)$ than "spread on purpose" beliefs $(r=0.42)$ with the endorsement of conspiracy theories that have been the subject of elite partisan (Republican/conservative, in this case) discourse, such as the theory that Barack Obama "faked his citizenship to become president." The opposite pattern is true when it comes to conspiracy theories that have not been widely and asymmetrically engaged by partisan elites, such as theories about the dangers of vaccines being "being hidden by the medical establishment" ( $r=0.39$ for "threat exaggerated;" $r=0.56$ for "spread on purpose"). In other words, these COVID-19 conspiracy beliefs are similar in their basic structure to conspiracy theories with different foci. 
- Threat Exaggerated, $\mathrm{R}^{2}=0.28$

- Spread on Purpose, $\mathrm{R}^{2}=0.40$

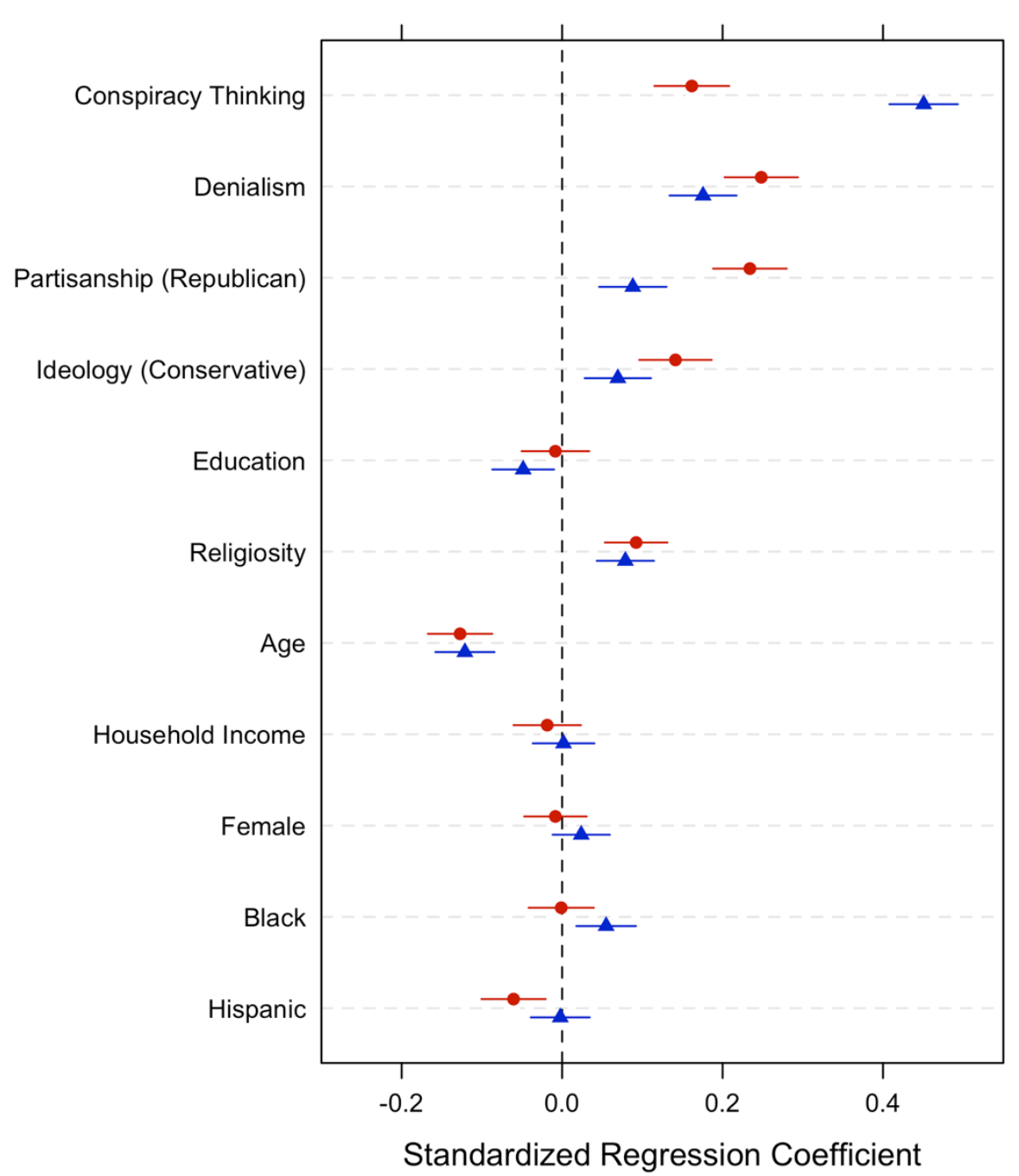

Figure 2. Predictors of COVID-19 conspiracy beliefs. Standardized ordinary least squares (OLS) regression coefficients, with 95\% confidence intervals where dependent variables are beliefs in COVID-19 conspiracy theories. The larger the absolute value of the coefficient (i.e., the farther a given plotting symbol is to the left or right or the dashed line, 0), the stronger the relationship between the independent variable (on the left) and COVID-19 conspiracy beliefs. $n=2,022$ for both models. 


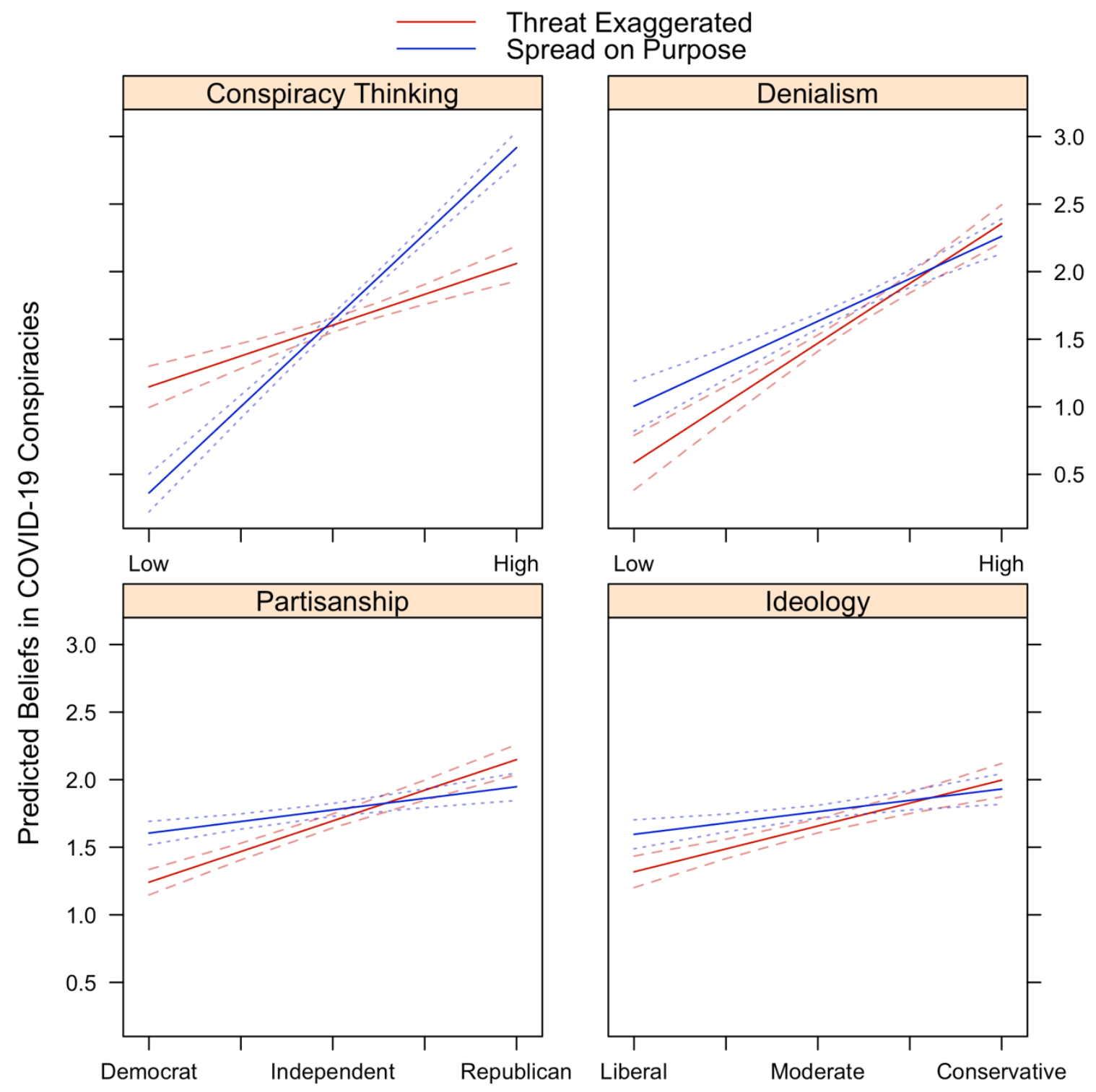

Figure 3. Predicted effects of conspiracy thinking, denialism, partisanship, and ideology. Other variables from the models presented in Figure 2 are held constant at their mean in generating predictions.

Finding 3: COVID-19 conspiracy beliefs are inflamed by partisan cues.

To further refine our understanding of the relationship between political predispositions and COVID-19 conspiracy beliefs, we consider the potential impact of partisan elites. Individuals with a pronounced dislike of Trump "disagree," on average, with the conspiracy theory, while sympathizers express something between neutrality and agreement (Figure 4, left panel). Furthermore, the strength of the relationship between Trump support and COVID-19 conspiracy beliefs is greater for individuals that closely follow politics (Figure 4, right panel). Such dynamics track the expectations of the "top down" model of public opinion formation, whereby elite discourse influences mass opinion (Zaller 1992). The 
more people pay attention to politics, the more likely they are to be exposed to messages from elites, thereby increasing the probability they will adopt those messages as beliefs. As Trump initially trivialized COVID-19, individuals who looked to him for guidance followed suit to a greater extent than those who did not (e.g., Democrats, those who pay less attention to politics).
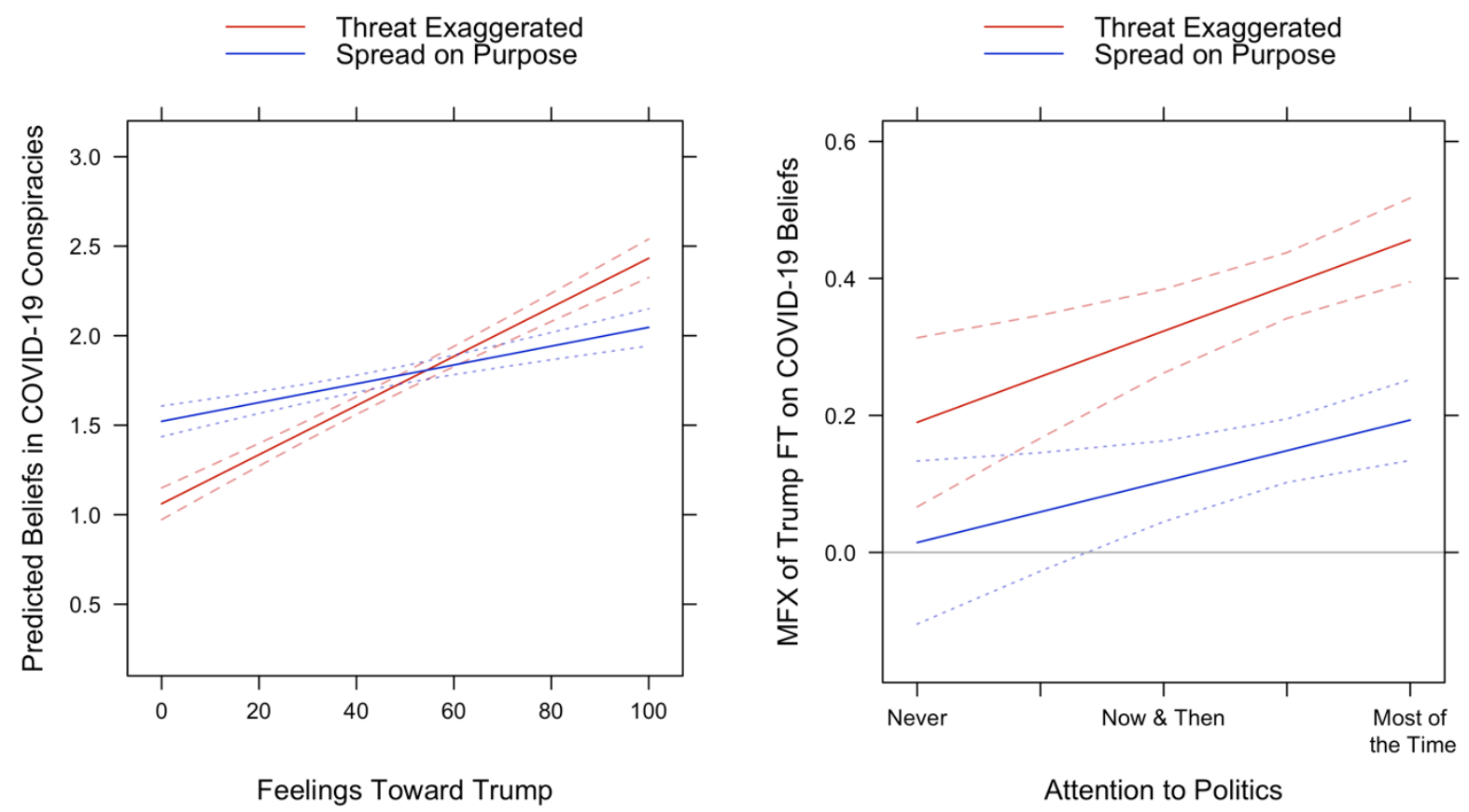

Figure 4. Relationship between COVID-19 conspiracy beliefs and Trump support. Predicted effects of Trump support (left) and marginal effects of Trump support conditional on attention to politics (right) on beliefs that COVID-19 "threat is exaggerated" and was "spread on purpose," controlling for other variables.

\section{Methods}

The survey was conducted between March 17-19, 2020; 2,023 adults were interviewed. Qualtrics administered the survey, partnering with Lucid and Dynata to recruit a sample that matched U.S. Census records on sex, age, race, and income. Lucid and Dynata maintain panels of subjects that are only used for research, and both comply fully with European Society for Opinion and Marketing Research (ESOMAR) standards for protecting research subjects' privacy and information. Only respondents who successfully passed two attention checks were retained and analyzed. This data collection was approved by the university Institutional Review Board. Details about precise demographic composition of the sample appear in the Supplemental Appendix.

The two key dependent variables ask respondents to what extent they agree/disagree, on a standard five-point Likert-type scale, with the following:

- The threat of coronavirus has been exaggerated by political groups who want to damage President Trump.

- Coronavirus was purposely created and released by powerful people as part of a conspiracy. 
Responses to these questions are correlated $(r=0.47, p<0.001)$. Although many conspiracy theories about COVID-19 have developed over the course of the pandemic, these two represent two of the earliest incarnations - one widely embraced by partisan political leaders, and another that blames the nefarious actions of some unknown group (some blame the Chinese, specifically, though this question wording does not require one to blame any specific conspirator). Question wording and variable coding regarding all independent variables is detailed in the Supplemental Appendix.

To understand the social and psychological correlates of conspiracy theories about COVID-19, we regressed both beliefs on measures of partisanship, ideology, educational attainment, religiosity, age, household income, gender, and race/ethnicity. We also included a scale of responses to survey items designed to capture conspiracy thinking (Uscinski, Klofstad and Atkinson 2016), the propensity to interpret events and information as the product of a conspiracy, and denialism, the propensity to reject expert, authoritative information and accounts of major events.

The items used to capture conspiracy thinking, which have been previously developed and validated by Uscinski, Klofstad and Atkinson (2016), are (coded 1-5, "strongly disagree" to "strongly agree"):

- Much of our lives are being controlled by plots hatched in secret places.

- Even though we live in a democracy, a few people will always run things anyway.

- The people who really 'run' the country, are not known to the voters.

- Big events like wars, the current recession, and the outcomes of elections are controlled by small groups of people who are working in secret against the rest of us.

The denialism items are (coded 1-5, "strongly disagree" to "strongly agree"):

- Much of the information we receive is wrong.

- I often disagree with conventional views about the world.

- Official government accounts of events cannot be trusted.

- Major events are not always what they seem.

The estimates presented in Figure 2 are the result of two OLS regression models: one with "threat exaggerated" beliefs as the dependent variable, the other with "spread on purpose" beliefs as the dependent variable. Each of the variables appearing along the left-hand, vertical axis of the figure are independent variables. Precise estimates from these models and those discussed below are presented in tabular form in the Supplemental Appendix.

To place the effects of conspiracy thinking, denialism, partisanship, and ideology in substantive context, we present the predicted level of both COVID-19 beliefs, across the scale of each of these predictors, in Figure 3. All other control variables are held constant at their mean values when generating predictions, as is the case in the analyses behind Figure 4 . Both conspiracy beliefs are coded to range from 0 (strongly disagree) to 4 (strongly agree). Considering the top left panel pertaining to conspiracy thinking (Figure 3), the predicted level of belief in the "spread on purpose" belief is just under 0.05 - close to 0 , or "strongly disagree" - at the very low end of conspiracy thinking. On the high end, however, the predicted belief is nearly 3 , or "agree."

Finally, we more carefully unpack the association between partisanship and conspiracy beliefs about COVID-19, especially focusing on the "threat exaggerated" belief. Because of the likely unique effect of Trump's rhetoric and behavior through March 2020, we added a measure of support for Trump to the models we displayed in Figure 2 (i.e., in addition to partisanship and ideology, both of which are already controlled for). Our measure of support is a feeling thermometer that asks respondents how "cold" (dislike) or "warm" (like) they feel toward Trump on a 0-100 scale. In the left panel of Figure 4, we plot the predicted effect of feelings toward Trump (holding other variables constant), just as we did with the 
other key predictors in Figure 3. Although feelings toward Trump are statistically significant in both models, we observe a stronger association in the "threat exaggerated" model.

To more carefully test the likelihood that Republicans and conservatives are expressing support for the COVID-19 conspiracy beliefs as a result of cues from Trump, we added a measure of attention to politics - a five-point scale ranging from those who "never" pay attention to those who pay attention "most of the time" - to the model and interacted it with feelings toward Trump. The marginal effects of the interaction on both COVID-19 conspiracy beliefs appear in the righthand panel of Figure 4 . The lines essentially represent the strength of the relationship between feelings toward Trump and conspiracy beliefs at different levels of attention to politics. The greater the marginal effect ( $y$-axis value), the greater the strength of association. In both instances, but most strongly with the "threat exaggerated" belief, the connection between feelings toward Trump and COVID-19 misinformation increases as attention to politics increases.

\section{Bibliography}

Badger, E., \& Quealy, K. (2020). American Partisanship May Find Its Limits in Coronavirus. The New York Times. Retrieved from www.nytimes.com website: https://www.nytimes.com/interactive/2020/03/21/upshot/coronovirus-publicopinion.html?auth=login-email\&login=email

Benegal, S. D., \& Scruggs, L. A. (2018). Correcting misinformation about climate change: the impact of partisanship in an experimental setting. Climatic change, 148(1), 61-80. doi:10.1007/s10584-018-2192-4

Berinsky, A. (2015). Rumors and Health Care Reform: Experiments in Political Misinformation. British Journal of Political Science, 47(2), 241-262. doi:10.1017/S0007123415000186

Brooks, B. (2020). Like the flu? Trump's coronavirus messaging confuses public, pandemic researchers say. Reuters. Retrieved from www.reuters.com website: https://www.reuters.com/article/us-health-coronavirus-mixed-messages/like-the-flutrumps-coronavirus-messaging-confuses-public-pandemic-researchers-sayidUSKBN2102GY

Carey, J. M., Chi, V., Flynn, D. J., Nyhan, B., \& Zeitzoff, T. (2020). The effects of corrective information about disease epidemics and outbreaks: Evidence from Zika and yellow fever in Brazil. Science Advances, 6(5), eaaw7449. doi:10.1126/sciadv.aaw7449

Douglas, K. M., Sutton, R. M., \& Cichocka, A. (2017). The Psychology of Conspiracy Theories. Current Directions in Psychological Science, 26(6), 538-542. doi:10.1177/0963721417718261

Jolley, D., \& Douglas, K. (2014). The Effects of Anti-Vaccine Conspiracy Theories on Vaccination Intentions. PLoS ONE, 9(2), e89177. doi:10.1371/journal.pone.0089177 
Miller, J. M., Saunders, K. L., \& Farhart, C. E. (2016). Conspiracy endorsement as motivated reasoning: The moderating roles of political knowledge and trust. American Journal of Political Science, 60(4), 824-844.

Nyhan, B., \& Reifler, J. (2019). The roles of information deficits and identity threat in the prevalence of misperceptions. Journal of Elections, Public Opinion and Parties, 29(2), 222-244. doi:10.1080/17457289.2018.1465061

Oliver, E., \& Wood, T. (2014). Medical Conspiracy Theories and Health Behaviors in the United States. JAMA Internal Medicine, 174(5), 817-818. doi:10.1001/jamainternmed.2014.190

Peters, J. W. (2020). Alarm, Denial, Blame: The Pro-Trump Media's Coronavirus Distortion. The New York Times. Retrieved from www.nytimes.com website: https://www.nytimes.com/2020/04/01/us/politics/hannity-limbaugh-trumpcoronavirus.html

Rieder, R. (2020). Trump and the 'New Hoax'. Factcheck.org. Retrieved from www.Factcheck.org website: https://www.factcheck.org/2020/03/trump-and-the-new$\underline{\text { hoaxl }}$

Roozenbeek, J., van der Linden, S., \& Nygren, T. (2020). Prebunking interventions based on "inoculation" theory can reduce susceptibility to misinformation across cultures. The Harvard Kennedy School (HKS) Misinformation Review. doi:https://doi.org/10.37016//mr-2020-008

Slotkin, J. (2020). U.K. Cellphone Towers Ablaze As Conspiracy Theories Link 5G Networks To COVID-19. NPR.org. Retrieved from www.npr.org website: https://www.npr.org/sections/coronavirus-live-updates/2020/04/04/827343675/u-kcellphone-towers-ablaze-as-conspiracy-theories-link-5g-networks-to-covid-19

Smallpage, S. M., Enders, A. M., \& Uscinski, J. E. (2017). The partisan contours of conspiracy theory beliefs. Research \& Politics, 4(4), 2053168017746554. doi:10.1177/2053168017746554

Stevenson, A. (2020). Senator Tom Cotton Repeats Fringe Theory of Coronavirus Origins. The New York Times. Retrieved from www.nytimes.com website: https://www.nytimes.com/2020/02/17/business/media/coronavirus-tom-cottonchina.html

Swire, B., Berinsky, A. J., Lewandowsky, S., \& Ecker, U. K. H. (2017). Processing political misinformation: comprehending the Trump phenomenon. Royal Society Open Science, 4(3). doi:10.1098/rsos.160802

Thorson, E. (2015). Belief Echoes: The Persistent Effects of Corrected Misinformation. Political Communication, 33(3), 460-480. doi:10.1080/10584609.2015.1102187 
Uscinski, J. E., Klofstad, C., \& Atkinson, M. (2016). Why Do People Believe in Conspiracy Theories? The Role of Informational Cues and Predispositions. Political Research Quarterly, 69(1), 57-71. doi:1065912915621621

Zaller, J. (1992). The Nature and Origins of Mass Opinion Cambridge, UK: Cambridge University Press.

Zaveri, M. (2020). Engineer Crashes Train Near Hospital Ship in Los Angeles. The New York Times. Retrieved from www.nytimes.com website: https://www.nytimes.com/2020/04/02/us/train-crash-los-angeles-coronavirus.html

\section{Funding}

This work is based on research supported by the University of Miami initiative on interdisciplinary inquiry.

\section{Competing interests}

The author(s) declared no potential conflicts of interest with respect to the research, authorship, and/or publication of this article.

\section{Ethics}

The University of Miami institutional review board approved this survey on 3/15/2020. Respondents were given an informed consent statement before beginning the survey and could opt out at any time. Gender and ethnicity were measured with standard questions to tie the sample to census data.

\section{Copyright}

This is an open-access article distributed under the terms of the Creative Commons Attribution License, which permits unrestricted use, distribution, and reproduction in any medium, provided that the original author and source are properly credited.

\section{Data Availability}

The Supplemental Appendix and all materials needed to replicate this study are available via the Center for Open Science: https://osf.io/ckanq/. 